\title{
A psychiatric emergency walk-in clinic: a dangerous substitute for primary care?
}

\author{
Jane F. Whittaker and Louis Appleby
}

\begin{abstract}
Data were collected on a six month sample of patients attending a poychiatic emergency walk-in clinic ( $n=378$ ), based on the cllinical impresstons of the Interviowing doctor. This information was then compared with a hypothotical model emergency service on the following tive liems: nature of patient problem, severtty of problem, clagnods, retering agent and current contoct with peychioticic services. The severity of the percelved threat to the interviewer was recorded. Only $4.7 \%$ of referrals contormed to the hypotheflcal model on all five crtterla. The majority of potients referred themselves, and the problems of selfreferrals were signilicantly less severe than those of general practitioner reterrats; $17.2 \%$ of consultations were percelved by the Interviewing doctor as presenting a moderate or severe threat to his or her sofoty. The findings suggest that such an emergency facilly operates as a form of primary care and b therefore inapproprlately used. The level of percelved threat to interviewing doctors is unacceptably high.
\end{abstract}

The management of urgent psychiatric cases is crucial to the future organisation of hospital and community services and the Department of Health (1989) has specified immediate admissions in psychiatry as one of the core services of the NHS. In most districts this is currently achieved through a hospital-based service, situated in either a general hospital accident and emergency department or in a separate psychiatric setting.

This study examines the operation of the latter kind of service in Manchester, comparing it to a hypothetical 'model' emergency clinic. Such a model service is assumed here to deal mainly with acute, severe problems arising in patients with major functional illness who do not easily have access to other psychiatric services and so present urgently, having been referred after being seen by their general practitioner.
Psychiatric emergencies can be threatening to staff but there has been little research on the impact of violence directed towards psychiatrists, usually those in junior grades who are called to attend urgent cases, although violence arising in in-patient settings has received detailed attention (Fottrell, 1980; Noble \& Rodgers, 1984). These studies suggested a three-point scale for rating the severity of physical assaults, but did not address verbal aggression or intimidating behaviour. This paper records the personal risk as percetved by junior doctors interviewing urgent psychiatric cases.

\section{The study}

Information about patients attending a psychiatric walk-in clinic was provided by the junior doctors by whom they were assessed. The clinic is based in the psychiatric unit of a large teaching hospital (Withington Hospital) and is known as In-Patient Reception (IPR). It is open from 9.00 a.m. to 10.00 p.m. seven days per week. Outside these hours patients are seen first in the hospital's Accident and Emergency Department. Patient attendances at In-Patient Reception are logged by a receptionist who then contacts the duty psychiatrist or the patient's own medical team. Psychiatric interviews take place in a room separated from the main corridor by a glass window. There is no waiting room.

The subjects in this study represent a six month consecutive sample of patients presenting to the IPR. After each consultation a questionnaire was completed, consisting of 20 items under four headings: the nature and severity of the presenting problem, source of referral, recent contact with psychiatric services and the subjective sense of perceived risk experienced by the interviewing doctor. In 
Table 1. Information about patients attending a psychiatric walk-in clinic

\begin{tabular}{|c|c|c|}
\hline Hem headings & $\begin{array}{l}\text { Responses supporting } \\
\text { hypothesis }\end{array}$ & $\begin{array}{l}\text { Responses not } \\
\text { supporting hypothesis }\end{array}$ \\
\hline \multicolumn{3}{|l|}{ Noture and severity of problem } \\
\hline Reason for referral & $\begin{array}{l}\text { Self harm } \\
\text { Acute distress } \\
\text { Disturbed behaviour }\end{array}$ & $\begin{array}{l}\text { Detoxification } \\
\text { Query over treatment }\end{array}$ \\
\hline Doctor's perception of severity & $\begin{array}{l}\text { Moderate } \\
\text { Severe }\end{array}$ & Mild \\
\hline Severity as implied by treatment & $\begin{array}{l}\text { Admission } \\
\text { Drug treatment }\end{array}$ & $\begin{array}{l}\text { 'Counselling' } \\
\text { (defined as any } \\
\text { psychological treatment) } \\
\text { No treatment }\end{array}$ \\
\hline Diagnosis & $\begin{array}{l}\text { Schizophrenia } \\
\text { Paranoid psychosis } \\
\text { Major depression } \\
\text { Mania }\end{array}$ & $\begin{array}{l}\text { Minor depression } \\
\text { Anxiety } \\
\text { Alcohol problem } \\
\text { Drug problem }\end{array}$ \\
\hline & General practitioner & $\begin{array}{l}\text { Self-referal } \\
\text { Referred by other agencies }\end{array}$ \\
\hline Contact with other senvices & $\begin{array}{l}\text { Not attending } \\
\text { Previous patient, not } \\
\text { being followed up }\end{array}$ & $\begin{array}{l}\text { Currently attending } \\
\text { Recent attendance at IPR }\end{array}$ \\
\hline Percelved dangerousness & No specific hypotheses & \\
\hline
\end{tabular}

most cases the questionnaires were completed within 24 hours of consultation and neither patient nor doctor was identifiable. The diagnoses recorded were made on conventional clinical grounds, rather than research criteria. The hypothesis of the study was that patients attending the service would conform to the hypothetical model outlined above. Specifically, this required that the majority of patients would:

(a) present with problems of a serious nature

(b) present with problems of at least moderate severity

(c) be suffering from a major functional illness

(d) have been referred by a general practitioner

(e) not be attending any other part of the psychiatric service.

Individual items are listed in Table 1, divided into whether or not they support one of the above hypotheses.

Although such criteria are necessarily rigid, they were thought to provide a broad description of the patient groups for whom iospital emergency services are designed.

\section{Findings}

Four hundred and seventy-three attendances were logged by the IPR receptionist in the study period. Three hundred and seventyeight forms were returned, a response rate of $78.9 \%$, the non-responders including patients who did not wait to be seen and an uncertain number of non-clinical enquiries. On some of the forms certain items had been omitted, and this accounts for the discrepancy in the total number of responses recorded in each results section.

Nature and severity of presenting problem The commonest main reason for presentation to IPR was acute distress (29.4\%) (see Table 2). One third of patients (32.3\%) were referred partly or entirely because of self harm; in half of these this risk was judged to be main reason for referral and in one in ten of all referrals this risk was judged to be moderate or severe. Almost one quarter of consultations (23.0\%) involved patients requesting detoxification or information about their treatment, reasons which do not support the hypothetical model service. Overall, two-thirds (65.4\%) of patients were judged to have problems of at least moderate severity. 
Table 2. Presenting problem

\begin{tabular}{|c|c|c|c|c|}
\hline \multirow[t]{2}{*}{ Nature of problem (n-378) } & \multicolumn{2}{|c|}{ Main problem } & \multicolumn{2}{|c|}{ Moderate or sever } \\
\hline & number & $\mathbf{x}$ & number & $\%$ \\
\hline $\begin{array}{l}\text { Self harm } \\
\text { Disturbed behoviour } \\
\text { Acute distress } \\
\text { Treatment request } \\
\text { Query over treatment } \\
\text { Dangerousness } \\
\text { 'Multiple' (no ranking) } \\
\text { Other } \\
\text { Not coded }\end{array}$ & $\begin{array}{r}63 \\
41 \\
111 \\
70 \\
17 \\
4 \\
28 \\
42 \\
2\end{array}$ & $\begin{array}{r}16.7 \\
10.8 \\
29.4 \\
18.5 \\
4.7 \\
1.1 \\
7.4 \\
11.1 \\
0.5\end{array}$ & $\begin{array}{r}39 \\
31 \\
85 \\
47 \\
4 \\
4 \\
21 \\
16 \\
7\end{array}$ & $\begin{array}{r}10.3 \\
8.2 \\
22.5 \\
12.4 \\
1.1 \\
1.1 \\
5.6 \\
4.2 \\
1.9\end{array}$ \\
\hline
\end{tabular}

Major functional illnesses (schizophrenia, paranoid psychosis major depressive disorders and mania) accounted for $41.6 \%$ of all consultations, whereas minor (as defined by the the model) illnesses and substance abuse accounted for $35.2 \%$. The latter figure is the percentage of cases which do not support the hypothetical model service.

More than a quarter of consultations led to admission (26.5\%), $2 \%$ of these under a section of the Mental Health Act. Almost a third (31.2\%) of consultations resulted in patients recelving drug treatments or having changes made to drug regimens. A quarter (25.1\%) recetved 'counselling' and $15.3 \%$ were said to recetve 'no treatment'. The latter two figures add up to over $40 \%$ of patient consultations where the patient did not receive treatments which were assumed to indicate severity, i.e. drugs or admission.
Support for this crude assumption was provided by cross tabulating perceived severity with type of treatment. Of those judged to be severe, $78 \%$ were admitted or received drugs; of those judged to be moderate severity, the figure was $63 \%$; for those judged to be of mild severity, the figure was $41 \%\left(\chi^{2}\right.$ 110.8 , d.f. $6, P<0.001$ ).

Of the $41.3 \%$ who were not already attending the service, most (33\% of the total) were referred for further psychiatric care.

\section{Source of referral}

Two-thirds (66.4\%) of consultations were with patients who had referred themselves. Only $24.4 \%$ had seen their GP prior to presentation and $20.6 \%$ had been referred by their GP. Community psychiatric services accounted for a minority of referrals and there were no

Table 3A. GP referrals v. self-referrals

\begin{tabular}{|c|c|c|c|c|}
\hline \multirow[t]{2}{*}{ Severtly } & \multicolumn{2}{|c|}{ EP referrals } & \multicolumn{2}{|c|}{ Selt-refornots } \\
\hline & number & $\%$ & number & 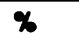 \\
\hline $\begin{array}{l}\text { All potients } \\
\text { Moderate/severe }\end{array}$ & $\begin{array}{l}78 \\
72\end{array}$ & $\begin{array}{r}100.0 \\
92.3\end{array}$ & $\begin{array}{l}251 \\
157\end{array}$ & $\begin{array}{r}100.0 \\
62.5\end{array}$ \\
\hline
\end{tabular}

$\chi^{2}$ 24.9, d.f. $1, P<0.0001$.

Table 3B. GP referrals v. self-referrals

\begin{tabular}{|c|c|c|c|c|}
\hline \multirow{2}{*}{ Treatment } & \multicolumn{2}{|c|}{ EP refemals } & \multicolumn{2}{|c|}{ Soll-reterials } \\
\hline & number & $\mathbf{x}$ & number & $\%$ \\
\hline $\begin{array}{l}\text { Admission } \\
\text { Drugs } \\
\text { Counselling } \\
\text { Zero }\end{array}$ & $\begin{array}{r}35 \\
22 \\
14 \\
7\end{array}$ & $\begin{array}{r}44.9 \\
28.2 \\
17.9 \\
8.9\end{array}$ & $\begin{array}{l}45 \\
86 \\
76 \\
44\end{array}$ & $\begin{array}{l}17.9 \\
34.3 \\
30.3 \\
17.5\end{array}$ \\
\hline
\end{tabular}

$\chi^{2} 24.5$, d.f. $3, P<0.0001$ 
Table 4. 'Sunvival analysis': sequential comparison with the five criteria for referral in a model emergency service

\begin{tabular}{lll}
\hline Crtterion & Number & Cumulative \% \\
\hline $\begin{array}{c}\text { Patlents with functional } \\
\text { psychosis or personality }\end{array}$ & 203 & 51.0 \\
$\begin{array}{c}\text { disorder } \\
\text { Who were not currently } \\
\text { attending }\end{array}$ & 52 & 14.0 \\
$\begin{array}{c}\text { Who were referred by } \\
\text { a general practitioner }\end{array}$ & 20 & 5.0 \\
$\begin{array}{c}\text { Whose problem was of } \\
\text { a serlous nature }\end{array}$ & 18 & 4.7 \\
$\begin{array}{c}\text { And of at least moderate } \\
\text { severtty }\end{array}$ & 18 & 4.7 \\
\hline
\end{tabular}

referrals at all from community psychiatric nurses. According to these results more than three-quarters of referalls did not conform to the hypothetical model.

GP and self-referrals were compared on problem severity and treatment offered. The results are shown in Tables $3 a$ and $3 b$. Referrals by GPs were significantly more likely to be judged as moderate or severe problems and were significantly more likely to receive treatment indicating severity.

Recent contact with psychiatric services

The percentage of patients new to psychiatric services and currently or previously attending was calculated; $40 \%$ were not currently attending the department. The majority of patients did not therefore conform on this item to the hypothetical model proposed: $6.6 \%$ (25 patients) had failed to attend an appointment in the previous month, $24.3 \%$ (92 patients) had attended IPR in the previous three months; $8.7 \%$ (33 patients) had both failed to attend a routine appointment and attended 'urgently'.

\section{Comparison with the hypothetical} model service

Table 4 combines some of the figures already given to produce a form of 'survival analysis', showing the number of patients who did not conform to the hypothesised model service at each stage in the process of clinical referral. Only $4.7 \%$ conformed on all five criteria.

\section{Perceived risk to interviewing doctor}

Table 5 shows the perceived personal risk of the doctors carrying out the interviews. This was a deliberately subjective evaluation, requested of the assessing doctor, to make a personal judgement of their perceptions of the potential risks they felt during an interview. Moderate or severe risk was percetved by the doctor in $17.2 \%$ of all consultations. Severe risk was perceived in $3.7 \%$ overall, with female doctors reporting severe risk twice as often as males (difference not significant on $\chi^{2}$ test).

In $17.7 \%$ of cases, supervision was requested by the doctor, and in $8.8 \%$ of requests it was reported to be unavailable.

\section{Comment}

The central finding of this study is that most patients who present to a psychiatric walk-in clinic do not conform to criteria defining who should attend such a service. If it is crudely assumed that no more than $25 \%$ of the patients should fail to conform on any one criterion, these results show that this limit is exceeded on severity, diagnosis, treatment need, source of referral and absence of current contact with psychiatric services. The $25 \%$ limit is met on only one item - the nature of the presenting problem. On some criteria, many more than $25 \%$ do not conform to the hypothetical model, particularly on source of referral-almost $80 \%$ were not referred by general practitioners. Most were self-referrals, these being less serious than GP referrals.

Table 5. Percelved personal risk

\begin{tabular}{|c|c|c|c|c|c|c|}
\hline \multirow{2}{*}{$\begin{array}{l}\text { Consultation } \\
(n-351)\end{array}$} & \multicolumn{2}{|l|}{ Low risk } & \multicolumn{2}{|c|}{ Moderate risk } & \multicolumn{2}{|l|}{ High risk } \\
\hline & number & $\mathbf{x}$ & number & $\%$ & number & $\%$ \\
\hline $\begin{array}{l}\text { Consultations by male doctors } \\
\text { Consultations by female doctors }\end{array}$ & $\begin{array}{l}170 \\
120\end{array}$ & $\begin{array}{l}83.3 \\
79.5\end{array}$ & $\begin{array}{l}29 \\
22\end{array}$ & $\begin{array}{l}14.2 \\
14.6\end{array}$ & $\begin{array}{l}5 \\
9\end{array}$ & $\begin{array}{l}2.5 \\
6.0\end{array}$ \\
\hline
\end{tabular}

$\chi^{2} 2.876$, d.f. 2, $P=0.2374$ 
When the main criteria are combined (Table $3)$, only $4.7 \%$ satisfy all five, but this figure should not be applied too strictly because, as noted previously, $10 \%$ of patients were at moderate or greater risk of self harm. Presumably all of these patients were appropriate referrals on purely clinical grounds but in many cases the source of referral did not match the prescribed model. Nevertheless, it is clear that by these broad criteria the majority of referrals to this walk-in clinic were not appropriate.

Criticisms can be made of this method, however. A number of forms were incomplete, although overall the response rate $(78.9 \%)$ appears satisfactory. The diagnoses are unstandardised, and some of the clinical impressions were subjective. They were, however, dertved from clinical practice and there is therefore a validity in what they imply about the organisation of a clinical service.

The five main criteria could be disputed, as some legitimate attenders would be excluded by them, e.g. a patient suffering from a panic attack would satisfy the criteria for nature of problem (acute distress) but not diagnosis. Nevertheless, the criteria were required to be clear, reliable and clinically relevant, and in our opinion represent the basic requirements of any emergency service.

The most debatable point is whether most referrals should come from a GP. We would argue that, in an integrated community, and hospital-based system, patients should not by-pass community services and go directly to a specialist level of service, the hospital psychiatrist. Initial assessments should take place in a primary care setting, which can then act as a filter of referrals leading to psychiatric hospital and ensure that there is some form of continuity of management. This does not necessarily mean that such assessment should be carried out by a general practitioner; mental health services and primary care are multidisciplinary and the general practitioner may be part of a broader community service (Jackson et al, 1993). Our results (Tables $3 a$ and $3 b$ ) show that GPs refer patients with more severe problems than selfreferrals, confirming one of their primary care roles as a filter for specialist services. In an 'ideal', integrated hospital - and communitybased service all patients would have access to a general practitioner, which would facilitate their rapid entry into specialist services if, in the opinion of their GP, they required it.
A further point about suitability of referrals concerns patients with personality disorder. In $12.4 \%$ of consultations personality disorder was the main diagnosis, and in this study these patients were included among those whose diagnosis indicated severity. Of the 47 personality disorder patients, 25 (53.2\%) were thought to have problems of at least moderate severity compared to $67.2 \%$ of all patients; but only $10(21.3 \%)$ were given treatments that were here assumed to confirm this severity. compared to $57.7 \%$ of all patients. Thus the finding of Lewis \& Appleby (1988), that personality disorder patients were regarded as less deserving of help, has received some support from clinical practice.

In almost one in five consultations junior doctors perceived themselves as being at moderate or severe risk. This issue has been the subject of a report by the Colleglate Trainees Committee Working Party (Royal College of Psychiatrists, 1991) which reported eight recommendations and raised a number of concerns including the risk of assessing patients in relative isolation without other staff to call upon and the observation that women doctors (and particularly those who are pregnant) might be most at risk. Our study underlines these points. Some psychiatric patients are dangerous and it is hard to say how often it is acceptable for staff (whether hospital or community based) to feel at a degree of personal risk. We would suggest that, unless sufficient back-up can be easily obtained, the only acceptable answer is that it should never knowingly occur. This is true whether the patients are seen in hospital, primary care or the community.

The emergency walk-in clinic described here is a single facility serving part of one city but it is likely to be comparable to similar services elsewhere in the country. The National Health Service is currently placing primary care in a central position in the control of referrals, and psychiatric services are increasingly community based. It is therefore vital that such hospital-based clinics are studied and evaluated further so that their most effective and efficient role within a broad mental health service can be determined. The role outlined here does not appear to be clinically efficient and appears to be unacceptably unsafe.

\section{References}

DEPARTMENT OF HEALTH (1989) Working for Patients. London: HMSO. 
FOTrREu, E. (1980) A study of violent behaviour among patients in psychlatric hospitals. British Journal of Psychiatry. 138, 216-221.

Jackson G. GATER, D. TANTAM D. et al (1993) A new community mental health team based in primary care: a description of the service and its effect on service use in the first year. British Journal of Psychiatry. 162, 375384

LEwS, G \& APPLEBY, L. (1988) Personality disorder: the patients psychiatrists dislike. Brttish Joumal of Psychiatry, 165, 44-49.

NoBle, P \& RODGers, S (1984) Violence by psychlatric inpatients. Brtish Journal of Psychiatry, 145, 384-390.
RoYal CoLnjae of Psychiatrists (1991) Report of the Colleglate Trainees' Committee Working Party on training of junior psychiatrists with respect to violent incidents. Psychiatric Bulletin, 16, 243-246.

Jane F. Whittaker, Registrar; and Louis Appleby, Senior Lecturer, Department of Psychiatry, Withington Hospital, West Didsbury, Manchester M20 8LR

\title{
Community care for people with learning disabilities: deficits and future plans
}

\author{
Nick Bouras, Geraldine Holt and Shaun Gravestock
}

\begin{abstract}
The challenge facing services for people with leaming disobilities is to create the environment in which clients have the best quality of lite without preconception. The heterogenous nature of people with leaming discablities requires diverstly of care provisions senstitive to their individual needs. The ditienent demonstrotion and presentation of their mental health needs has influenced the development of services and different models of speclallst services have emerged with local variations. There is still, however, a great deal of contustion on both ideological and service dellvery lovel. Athough services for people with leaming discbillties hove succeeded in resettiling people in the community and supporting them in doveloping odcptive skills, uniortunately these successes are not matched by equally effective and efficient services to those with mental heatth needs.
\end{abstract}

The functioning of people with learning disabilities is affected by many factors other than their intellectual impairments. Their ability to communicate and their social competency also influence their behaviour and adjustment. People with learning disabilities may require support to live an independent life but the challenge facing services is to create the environment that will provide them with the best quality of life while maximising developmental opportunities.

\section{Community care}

Successive policy initiatives since the 1970 s have led to the resettlement of people with learning disabilities from long-stay hospitals into the community. In the 1980 s issues arising from the 'normalisation' (social valorisation), consumers' rights, self-advocacy and quality assurance movements have radically influenced the service models developed for people with learning disabilities. The focus on ordinary housing also highlighted the role of the housing departments of local authorities, housing associations and voluntary organisations while increasing the use of social security benefits. The Community Care Act (Department of Health, 1989) consolidated the interface between health, social services and voluntary agencies.

People with learning disabilities vary from those who have a mild degree of intellectual disability but are physically normal, to those who have severe and multiple disabilities requiring specialist care. Unfortunately none of the existing classification systems provide a satisfactory framework to assess the service requirements of people with learning disabilities (Anness et al, 1991). 